\title{
Chlorophyll a fluorescence in two varieties of sugar cane subjected to aluminum and water stress
}

\author{
Martios Ecco ${ }^{1 *}$, Etenaldo Felipe Santiago ${ }^{2}$ and Paulo Ricardo Lima ${ }^{3}$ \\ ${ }^{1}$ Universidade Estadual de Mato Grosso do Sul. Rodovia Aquidauana/UEMS - Km 12 - Aquidauana-MS, 79200-000, \\ Brazil. \\ ${ }^{2}$ Universidade Estadual de Mato Grosso do Sul - Cidade Universitária de Dourados, Dourados-MS, 79804-220, Brazil. \\ ${ }^{3}$ Faculdade Integrado de Campo Mourão, Rodovia BR 158, KM 207 - Campo Mourão - PR, 87300-970, Brazil.
}

Accepted 17 September, 2013

\begin{abstract}
Soils of open pasture in the Cerrado (brazilian savanna) have farming limitations related to the high content of aluminum and water restrictions in the superficial horizons, due to easy drainage and large exposure to high levels of irradiance. Aiming to assess chlorophyll a fluorescence's responses in two varieties of sugar cane in the State of Mato Grosso do Sul subjected to water restriction and different aluminum contents, an experiment was conducted in a controlled environment. The experimental lineation consisted of random blocks in a factorial scheme ( 2 varieties $\times 2$ levels of water available in the soil based on field capacity [cc] and 3 contents of $\mathrm{Al}^{+3}$ ), with 15 replications. Significant differences were observed throughout and at the end of the experiment between the averages of some parameters of chlorophyll a fluorescence for treatment EH1 and between varieties. Results obtained by means of the OJIP test were the most efficient for variety distinction. RB1 (RB 8555536) proved to be more responsive to treatments, variety RB2 (RB867515) did not present significant alterations between treatments; its suggests that most part of the radiation was efficiently used in the photochemical stage of photosynthesis, that makes it more tolerant to the subjected stresses.
\end{abstract}

Key words: Saccharum spp, Cerrado, photosynthesis.

\section{INTRODUCTION}

Brazil is the greatest producer of sugar cane in the world with a production of $571,471.0$ million tons, in an area of 8,368.4 million hectares, according to the National Supply Company - CONAB (2011). The country leads the use of this plant as a source of renewable liquid energy: alcohol, which is used as an alternative fuel for vehicles, besides being an energetic plant used in human and/or animal nourishment.

In the soils of Cerrados (brazilian savanna) it is usually possible to verify farming limitations related to high content of aluminum, water restrictions in the superficial horizons due to easy drainage and large exposure to high levels of irradiance (Konrad et al., 2005). According to Tang et al. (2003) the exchangeable aluminum reduces the root apex growth thus impeding the access to water and nutrients in deeper soil layers and aggravating the development limitation caused by water unavailability (Steudle, 2000).

Photosystem II (PSII) is the component of the photosynthetic complex having an essential role in the 
Table 1. Analysis of soil from the experimental area of the UEMS, Unit Aquidauana / MS, used as substrate for installation of the study. Laboratory analysis of soil fertility (IAGRO, 2010).

\begin{tabular}{lccccccccccc}
\hline $\begin{array}{l}\text { Sample } \\
\text { (cm) }\end{array}$ & $\mathbf{p H}$ & $\begin{array}{c}\mathbf{P} \\
\mathbf{m g} / \mathbf{c m}^{\mathbf{3}}\end{array}$ & $\begin{array}{c}\mathbf{M} . \mathbf{O} \\
\%\end{array}$ & $\mathbf{K}$ & $\mathbf{C a}$ & $\mathbf{M g}$ & $\mathbf{A l}$ & $\mathbf{S}$ & $\mathbf{T}$ & $\mathbf{m}$ & $\mathbf{V}$ \\
\hline $0-20$ & 6.1 & 32.2 & 3.5 & 0.34 & 5.7 & 2.0 & 0.0 & 8.0 & 11.0 & 0.0 & 72.8 \\
$20-40$ & 6.2 & 21.2 & 2.2 & 0.20 & 4.7 & 1.5 & 0.0 & 6.4 & 8.80 & 0.0 & 72.7 \\
\hline
\end{tabular}

$\mathrm{M} . \mathrm{O}=$ organic matter, $\mathrm{T}=\mathrm{CTC}=$ cation exchange capacity, $\mathrm{m}=$ aluminum saturation, $\mathrm{V}=$ Base saturation.

response to environmental stress (Tester and Bacic, 2005). Among the techniques developed for the study of structure and behavior of the photosynthetic system, one can highlight those that investigate chlorophyll a fluorescence.

Fluorescence is one of the three ways of dissipating energy; it consists in the small fraction of energy dissipated as light by chlorophyll molecules which may be altered by several factors, such as suboptimal conditions of plant development (Strasser et al., 2004). Any alterations in fluorescence may indicate disturbances in the photosynthetic process (Baker and Rosenqvist, 2004). Relatively fast responses of photochemical efficiency $(\mathrm{Fv} / \mathrm{Fm})$ to stress might be an important tool in the selection of sugar cane varieties tolerant to drought and toxic elements like Al (Silva et al., 2007). A well accepted concept states that measures for Chl-a fluorescence may be used as a tool to diagnose the integrity of the photosynthetic complex against environmental adversities. Moustakas et al. (1995) concluded that Al caused a decrease in photosynthesis, as a result of the closing of PSII reaction centers (RCS) and of a reduction in the electron transport rate in PSII, as well as an increase in photorespiration.

Taking into account the reduced water availability and the presence of toxic elements in the Cerrado region, the sugar cane response to draught and $\mathrm{Al}$ is the high priority topic which needs detailed investigations. Chl-a fluorescence may provide an efficient, fast and practical tool to overcome the problems of the Brazilian agribusiness caused by these environmental stresses (Silva et al., 2007). The present work aimed to assess the responses of Chl-a fluorescence in young plants from two sugar cane varieties in the State of Mato Grosso do Sul Brazil which were subjected to water stress and different levels of aluminum, in a controlled environment.

\section{MATERIALS AND METHODS}

\section{Installation procedures}

The work was carried out in a greenhouse, between coordinates $20^{\circ} 27^{\prime} 20^{\prime \prime}$ latitude $S$ and 55'40'17" longitude W, and average altitude of $174 \mathrm{~m}$. As for the experimental design, the used method consisted of random blocks in a factorial scheme (2 varieties $\times 2$ levels of water available in the soil based on field capacity [cc] and 3 contents of $\mathrm{Al}^{+3}$ ), with 15 replications, totalizing 12 treatments and
180 containers.

We used RB855536 and RB867515 varieties of sugar cane mentioned in this work as RB1 and RB2, respectively. They were collected in an Alcohol and Sugar Factory (ETH Bioenergia), located in the municipality of Rio Brilhante/MS. The whole culms of both varieties (RB1 and RB2) were sectioned in small parts named "setts" which contained two buds $( \pm 25 \mathrm{~cm})$. Two setts were planted in each container (black polyethylene, with capacity of 5 l) which kept as substratum a moderate A Eutrophic Yellow Red Argisol, with medium/clayey texture whose composition (determined by Mehlich 1 method) is presented on Table 1. Water levels were defined as control (70 to $90 \%$ CC) and water stress (20 to $40 \%$ $\mathrm{CC})$. In order to develop this definition, the direct method (MD) was used in vases. For such method, the considered field capacity (CC) was the content of water kept by the vase's soil after having been through saturation and, consequently, gravity action; it was calculated daily by weight difference with the use of a precision scale. Different dosages of aluminum were applied: 0 and 0.2 and $0.4 \mathrm{mmol} \mathrm{L}^{-1}$ as $\mathrm{Al}_{2}\left(\mathrm{SO}_{4}\right)_{3} \cdot 18 \mathrm{H}_{2} \mathrm{O}$ based on a study by Konrad et al. (2005) concerning to the culture of coffee trees. $100 \mathrm{ml}$ of the solution were applied to each vase with the use of a beaker via soil, given that the first application happened 5 days after the plantation and the second one, 18 days after the emergence (DAE). The treatments were designated as follows: (C) - Control, (SE) - No water stress; $(\mathrm{EH})$ - water stress; (1) Dose $0.2 \mathrm{mmol} \mathrm{L}^{-1}$ of $\mathrm{Al}$ and (2) - Dose $0.4 \mathrm{mmol} \mathrm{L}^{-1}$ of Al.

\section{Physiological components measurement}

Chlorophyll a fluorescence variables were analyzed, as well as the phenomenological flow parameters and the OJIP transients with the use of a Handy PEA Hansatech fluorimeter. The variables observed during the measurement of Chlorophyll a fluorescence were: initial, basal or minimum fluorescence $\left(F_{0}\right)$ - the fluorescence when all reaction centers are open, $(\mathrm{Fm})$ - the fluorescence when all reaction centers are closed, (Fv) - variable fluorescence, determined by the reaction center's state (open or closed), (Fv/Fm) - efficiency or maximum quantum yield of PSII, and (PI) - performance or development index. The phenomenological flow parameters assessed in this work were: $\mathrm{RC} / \mathrm{CS}$ = reaction centers' density per cross-section; ABS/CS = number of photons absorbed per cross section; $\mathrm{Dlo} / \mathrm{CS}$ = dissipation energy per cross-section; $\mathrm{ETo} / \mathrm{CS}=$ electron transport per cross-section (Gonçalves et al., 2010).

\section{Physiological component analysis}

It was possible to obtain the OJIP curve area. OJIP transient is a tool used to analyze the kinetic changes in chlorophyll $a$ fluorescence. It also provides detailed information on the structure and function of the photosynthetic complex, especially of photosystem II (Gonçalves et al., 2010). The (O-J) stage corresponds to a complete reduction of the main electron receptor of PSII (Qa). The $(\mathrm{J}-\mathrm{I})$ stage corresponds to the electron transfer 
Table 2. Chlorophyll fluorescence parameters of Saccharum spp. young plants [RB1 (RB 8555536) variety]. Given are the means.

\begin{tabular}{lccccc}
\hline Treatments & Fo & Fm & Fv & Fm/Fv & PI \\
\hline C & $342.4^{\mathrm{a}}$ & $1392.4^{\mathrm{a}}$ & $1050.0^{\mathrm{a}}$ & $0.757^{\mathrm{a}}$ & $6.5^{\mathrm{a}}$ \\
SE1 & $370.5^{\mathrm{a}}$ & $1398.0^{\mathrm{a}}$ & $1027.5^{\mathrm{a}}$ & $0.751^{\mathrm{a}}$ & $5.7^{\mathrm{a}}$ \\
SE2 & $304.7^{\mathrm{a}}$ & $1375.6^{\mathrm{a}}$ & $1070.9^{\mathrm{a}}$ & $0.778^{\mathrm{a}}$ & $6.0^{\mathrm{a}}$ \\
EH & $280.3^{\mathrm{a}}$ & $1302.2^{\mathrm{a}}$ & $1021.8^{\mathrm{a}}$ & $0.779^{\mathrm{a}}$ & $5.6^{\mathrm{a}}$ \\
EH1 & $271.7^{\mathrm{a}}$ & $1157.9^{\mathrm{b}}$ & $886.3^{\mathrm{b}}$ & $0.759^{\mathrm{a}}$ & $3.6^{\mathrm{b}}$ \\
EH2 & $304.0^{\mathrm{a}}$ & $1336.2^{\mathrm{a}}$ & $1032.2^{\mathrm{a}}$ & $0.772^{\mathrm{a}}$ & $5.5^{\mathrm{a}}$ \\
\hline
\end{tabular}

Means followed by same letter in columns do not differ statistically from each other at $5 \%$. (Fo) - initial fluorescence, (Fm) maximum fluorescence $(\mathrm{Fv})$ - variable fluorescence, (Fv/Fm) - efficiency or maximum quantum yield of PSI, and (PI) performance or development index.

from $\mathrm{Qa}$ to $\mathrm{Qb}$, and the (I-P) stage corresponds to the liberation of fluorescence (Abbaspoor and Streibig, 2005).

Chlorophyll a fluorescence determinations were performed in half a lamina of the leave +1 (first leaf with visible insertion) totally expanded, counted from the apex, at 30;60;90 and 120 days (December/2010 to March/2011), in the period between 07:30 and 09:00 am. Before each assessment the leaves were adapted to dimness for 30 min with the use of leaf clips.

\section{Statistical analysis}

Data were subjected to variance analysis by the Kruskal-Wallis method, and the averages were compared to each other by the Dunnet test with the support of statistical software Bioestat.

\section{RESULTS AND DISCUSSION}

Significant differences were verified between averages of some basic parameters of chlorophyll a fluorescence throughout the experiment and at the end of it, between treatments and between varieties. Variety RB1 (RB 8555536) has proved to be more responsive to treatment EH1: only averages for the initial fluorescence and quantum efficiency of photosystem II did not vary at the end of the experiment (Table 2) and the lowest average values for parameters Fv, Fm and PI were observed in treatment EH1. As for variety RB2 (RB867515), there were no significant differences between averages for the same parameters.

It is known that the reduction in available water content generally influences the potential photochemical efficiency of photosystem II (PSII), assessed by means of the relation $\mathrm{Fv} / \mathrm{Fm}$. This effect was also shown at sugar cane varieties (Gonçalves et al., 2010). In the present study, no significant differences were observed in any of the varieties for this parameter.

Bolhàr-Nordenkampf et al. (1989) report that when the plant keeps its photosynthetic complex intact, the ratio $\mathrm{Fv} / \mathrm{Fm}$ must vary between 0.75 and 0.85 while a decrease in this ratio indicates the presence of photoinhibition in the reaction centers of PSII. The values of $\mathrm{Fv} / \mathrm{Fm}$ observed in the varieties that were subjected to Control treatment $(<0.8)$ despite being within the previously mentioned amplitude, differ from those presented by Silva et al. (2007), who found ratios that were higher than 0.8 in sugar cane genotypes under complete hydration. Such discrepancy may be the result of many factors, like assessment time and specific climatic conditions of each study environment. One can find distinct results in Literature in what concerns to the relation $\mathrm{Fv} / \mathrm{Fm}$ in response to reduction in the soil's water availability. According to Silva et al. (2007), significant genotype by irrigation $(\mathrm{GxW})$, genotype by evaluation date $(\mathrm{G} \times \mathrm{D})$ and irrigation by evaluation date $(\mathrm{W} \times \mathrm{D})$ interactions were observed for Fv/Fm measurements. Molinari et al. (2007), in a study on lineages of transgenic sugarcane, observed a $65 \%$ higher difference from control plants in water stress, for this parameter.

On the other hand, Ghannoum et al. (2003) did not find significant alterations in the relation $\mathrm{Fv} / \mathrm{Fm}$ in four species of cycle C4 grass, what indicates that the transport capacity of the electrons had not been altered due to water stress.

In the study carried out by Konrad et al. (2005) on the culture of coffee trees, the ratio $\mathrm{Fv} / \mathrm{Fm}$ with $\mathrm{Al}(0.148$ $\mathrm{mmol} \mathrm{L}^{-1}$ ) decreased averagely by $13 \%$ in comparison to the control. However, they did not find difference between cultivars. Witnesses were similar to each other and plants with Al were also similar to each other.

In the present work, however, in what concerns to variety RB867515 (RB2), no significant alterations were found between treatments, for any of the fluorescence variables, what suggests that most PAR was efficiently used in the photochemical stage of the photosynthesis, with no harm in PSIl due to water stress or aluminum (Table 3). The ability to keep similar Fv/Fm values under water stress may indicate high efficiency in the usage of radiation, possibly because of carbon assimilation (Silva et al., 2007).

The Development Index (PI) has been considered as a more responsive parameter for the detection and quantification of stress in plants than the maximum efficiency response of photosystem II (FV/Fm) (Oukarroum et al., 2007), in other words, more consistency for the interpretation of results has been obtained when PSII's 
Table 3. Chlorophyll fluorescence parameters of Saccharum spp. young plants [RB2 (RB 867515) variety]. Given are the means.

\begin{tabular}{lccccc}
\hline Treatments & Fo & Fm & Fv & Fv/Fm & PI \\
\hline C & $292.557^{\mathrm{a}}$ & $1275.333^{\mathrm{a}}$ & $982.776^{\mathrm{a}}$ & $0.770^{\mathrm{a}}$ & $5.500^{\mathrm{a}}$ \\
SE1 & $295.897^{\mathrm{a}}$ & $1297.378^{\mathrm{a}}$ & $1001.481^{\mathrm{a}}$ & $0.771^{\mathrm{a}}$ & $5.804^{\mathrm{a}}$ \\
SE2 & $301.381^{\mathrm{a}}$ & $1329.762^{\mathrm{a}}$ & $1028.381^{\mathrm{a}}$ & $0.773^{\mathrm{a}}$ & $5.959^{\mathrm{a}}$ \\
EH & $292.176^{\mathrm{a}}$ & $1210.067^{\mathrm{a}}$ & $917.891^{\mathrm{a}}$ & $0.756^{\mathrm{a}}$ & $4.361^{\mathrm{a}}$ \\
EH1 & $299.569^{\mathrm{a}}$ & $1266.206^{\mathrm{a}}$ & $966.637^{\mathrm{a}}$ & $0.762^{\mathrm{a}}$ & $4.728^{\mathrm{a}}$ \\
EH2 & $305.599^{\mathrm{a}}$ & $1344.480^{\mathrm{a}}$ & $1038.881^{\mathrm{a}}$ & $0.772^{\mathrm{a}}$ & $5.257^{\mathrm{a}}$ \\
\hline
\end{tabular}

Means followed by same letter in columns do not differ statistically from each other at $5 \%$. (Fo) - initial fluorescence, (Fm) maximum fluorescence (Fv) - variable fluorescence, (Fv/Fm) - efficiency or maximum quantum yield of PSII, and (PI) - performance or development index.

response is assessed for stress conditions by using the $\mathrm{PI}$ than by only the ratio FV/Fm. That happens because this variable relates absorption efficiency and captures the excitation energy transference by photosystem II, providing a broader view of the effect's degree of the stressing environment (Gonçalves and Santos Júnior, 2005).

In the present study, the reductions observed in $\mathrm{PI}$ happened due to the water restriction associated with the first dosage of aluminum, in other words, the interaction between water stress and lower dosage of aluminum promoted the most effective response of PI reduction in the RB1 most susceptible variety (Table 2 ).

According to Thach et al. (2007), the significant decrease of $\mathrm{PI}$ values indicates an effect of photoinhibition, and such changes represent loss of photochemical efficiency by plants. Even though a significant reduction was verified in treatment EH1's performance, the elevation of PI in the higher dosage of Al suggests the interference of this element in the relations of energy absorption and electron transfer in PSII. Indeed, by analyzing the phenomenological flow parameters (excitation variables per cross-section - CS) (Tables 4 and 5), can be noticed that changes in the means values of absorption flow (ABS/CS), electron transport flow (ETo/CS), and excited reaction centers $(\mathrm{RC} / \mathrm{CSm})$, per cross-section, are related to aluminum doses, it suggests interferences in the flow of energy through PSII molecules.

Changes in RC/CSm apparently are associated with variations in the flow of energy in PSII, so as the relations of absorption and electron transfer, although it was not detected amendments in the non-photochemical quenching processes. Gonçalves et al. (2012) suggested that the flow of light energy into $G$. spruceana seedlings under total flooding, at the beginning, it was more restricted by a light harvesting structure decrease than in the functioning of the photosynthetic complex. Similarly to these authors, was observed differences between the density of molecules in the reaction center and the time of experimentation. By comparing the averages of the excitation variables per cross-section in the beginning of the experiment and after 90 days (Figure 1) one can clearly verify that water stress (EH) affects the excitation variables per cross-section (CS) in both sugar cane varieties.

The comparison of average parameters of chlorophyll a excitation variables per cross-section (CS) by young plants of Saccharum spp from variety RB 867515 (RB2) only showed significant differences in what concerns to the density of excited reaction centers (RC/CSm). In fact, the $\mathrm{RC} / \mathrm{Csm}$ differed between varieties and over experimental time, with reductions of 28.11 and $16 \%$ for RB1 and RB2 (respectively) in the EH condition (Figure 1 ), and 32.33 and $27.39 \%$ for the same varieties in the $\mathrm{EH} 2$ treatment (Figure 2).

Despite the behavior of the varieties in the water stress condition being similar (Figure 1) and the excitation variables of chlorophyll a per cross-section (CS) in variety RB2 suggesting a better adjust of this variety to different experimental conditions (Table 5), by analyzing the water stress in the higher dosage of Al (Figure 2), one can see that the behavior of both varieties remains similar. The interference mechanisms of $\mathrm{Al}$ in the relations of energy absorption and electron transfer in PSIl are not very clear. When in high concentrations, metals may cause a range of significantly different effects (Ralph and Burchett, 1998) like changes in both electron transfer and enzyme activities (Li et al. 2010). Barazzouk et al. (2005), based on electrochemical studies, attributed the effect of photoinducted electron transfer of excited chlorophyll to nanoparticles of gold. For these authors, electron transfer is a dominant process when one considers the differences in chlorophylls' oxidation potential. Nanoparticles of gold are capable of interfering in electron dissipation processes in PSII (Caires et al., 2010), similarly, aluminum nanoparticles are able to induce toxic effects related to interaction between the particles and the surface active sites on the cell wall (Sadiq et al., 2011) but these ANPs are infinitely larger compared with ions. Some stress responses are related to $\mathrm{Al}^{3+}$ ions released from ANPs in the medium playing a predominant role on cytotoxicity (Pakrashi et al., 2013).

Aromatic molecules or organometallic complexes may 
Table 4. Chlorophyll a variable excitation parameters per cross section (CS) in Saccharum spp. young plants [RB1 (RB 855536) variety]. Given are the means.

\begin{tabular}{lcccc}
\hline Treatments & ABS/CS & ETo/CS & Dlo/CS & RC/CSm \\
\hline C & $306.182^{\mathrm{a}}$ & $166.994^{\mathrm{a}}$ & $71.326^{\mathrm{a}}$ & $761.299^{\mathrm{a}}$ \\
SE1 & $310.646^{\mathrm{a}}$ & $168.191^{\mathrm{a}}$ & $75.047^{\mathrm{a}}$ & $706.149^{\mathrm{a}}$ \\
SE2 & $310.220^{\mathrm{a}}$ & $162.935^{\mathrm{ab}}$ & $74.139^{\mathrm{a}}$ & $704.569^{\mathrm{ab}}$ \\
EH & $294.583^{\mathrm{ab}}$ & $162.754^{\mathrm{ab}}$ & $67.990^{\mathrm{a}}$ & $684.081^{\mathrm{ab}}$ \\
EH1 & $277.804^{\mathrm{b}}$ & $153.360^{\mathrm{b}}$ & $65.351^{\mathrm{a}}$ & $616.961^{\mathrm{b}}$ \\
EH2 & $306.134^{\mathrm{a}}$ & $161.429^{\mathrm{ab}}$ & $74.753^{\mathrm{a}}$ & $657.700^{\mathrm{ab}}$ \\
\hline
\end{tabular}

Means followed by same letter in columns do not differ statistically from each other at $5 \%$. RC/CS $=$ reaction centers' density per cross-section; $\mathrm{ABS} / \mathrm{CS}$ = number of photons absorbed per cross section; $\mathrm{Dlo} / \mathrm{CS}=$ dissipation energy per cross-section; ETo/CS = electron transport per cross-section.

Table 5. Chlorophyll a variable excitation parameters per cross section (CS) in Saccharum spp. young plants [RB2 (RB 867515) variety] given are the means.

\begin{tabular}{lllll}
\hline Treatments & ABS/CS & ETo/CS & Dlo/CS & RC/CSm \\
\hline C & $294.662^{\mathrm{a}}$ & $162.947^{\mathrm{a}}$ & $68.487^{\mathrm{a}}$ & $699.041^{\mathrm{ab}}$ \\
SE1 & $298.761^{\mathrm{a}}$ & $167.556^{\mathrm{a}}$ & $69.594^{\mathrm{a}}$ & $721.809^{\mathrm{ab}}$ \\
SE2 & $302.413^{\mathrm{a}}$ & $170.778^{\mathrm{a}}$ & $68.933^{\mathrm{a}}$ & $757.191^{\mathrm{a}}$ \\
EH & $298.550^{\mathrm{a}}$ & $162.712^{\mathrm{a}}$ & $74.849^{\mathrm{a}}$ & $624.888^{\mathrm{b}}$ \\
EH1 & $293.887^{\mathrm{a}}$ & $156.464^{\mathrm{a}}$ & $70.522^{\mathrm{a}}$ & $671.701^{\mathrm{ab}}$ \\
EH2 & $303.445^{\mathrm{a}}$ & $167.352^{\mathrm{a}}$ & $69.475^{\mathrm{a}}$ & $735.792^{\mathrm{ab}}$ \\
\hline
\end{tabular}

Means followed by same letter in columns do not differ statistically from each other at $5 \%$. RC/CS = reaction centers' density per cross-section; $\mathrm{ABS} / \mathrm{CS}$ = number of photons absorbed per cross section; $\mathrm{Dlo} / \mathrm{CS}=$ dissipation energy per cross-section; ETo/CS = electron transport per cross-section.

interact with electrochemical cells, in which the adsorbate is responsible for the optical properties of the system. The metallic oxide adsorbed, apart from supporting the adsorbate, also allows the passage of electrons (Thavasi et al., 2009). On the other hand, the usual aluminum effect in vegetal cells is inhibition of enzyme activity and PSII activity (Raij et al., 1998).

In the present study, the increase on $\mathrm{EH} 2$ (ABS/CS), $(\mathrm{ETo} / \mathrm{CS})$ and $(\mathrm{RC} / \mathrm{CSm})$, averages comparing with $\mathrm{EH} 1$ treatment, suggests changes on PSII energy flow in the RB 855536 variety. These adjustments on Al-treated plants could not be attributed always to decrease activities of Calvin-Benson cycle enzymes (Chen et al., 2005). In sugar cane, the activity of nitrate reductase, for exemple is indicative only water stress effect, but not aluminum (Carlin et al., 2012). Konrad et al. (2005) associated the increase of non-photochemical dissipation to Al stress responses in coffee trees. In our study, similar to that observed by Chen et al. (2005), non photochemical dissipation did not have a central role in dissipating energy in Al-treated leaves. In Citrus leaves the Al-induced inhibition of electron transport due to changes in trap capacity more than Maximum quantum yield in response to the Al treatments (Jiang et al., 2008).

The potential effects of sulfur cannot be ignored considering that in a dose $0.4 \mathrm{mmol} \mathrm{L}^{-1}$ of $\mathrm{Al}$ is included also the increase in the amount of sulfur in $\mathrm{SO}_{4}$ form. It is known that $S$ has significant role in the mechanisms of absorption of ions nutrients (Astolfi et al., 2010) and besides being crucial in the synthesis of amino acids, proteins (including major and D2-D1 Protein) and chlorophyll (Godde and Dannehl, 1994) its soil displacement and role in reducing the toxic effects of aluminum has been found to explain the productivity increase in sugar cane (Silva et al., 2007), which requires further investigation about the effect of this element on fluorescence chlorophyll parameters, especially in Saccharum spp physiological studies. Among the fluorescence parameters of chlorophyll a approached in this study, the results obtained by means of the OJIP test were the most efficient for the distinction of varieties (Figures 3 and 4).

Even though both varieties have presented some tolerance to aluminum and to water stress in the dosages used and in the tested conditions, the analysis of average curves of fluorescence in the OJIP test evidenced the differences between varieties as well as loss of curve sigmoidicity from step $\mathrm{J}$ on in plants kept under water stress (Figure 3). The typical polyphasic rise in Chl-a fluorescence is modified in Al-treated plants, in this case, it that show a large increase at the O-step and a large depression at the P-step, promoting an heterogeneity in the OJIP transient (Jiang et al., 2008). OJIP fluorescence kinetic is a very useful tool in the in vivo analysis of the 

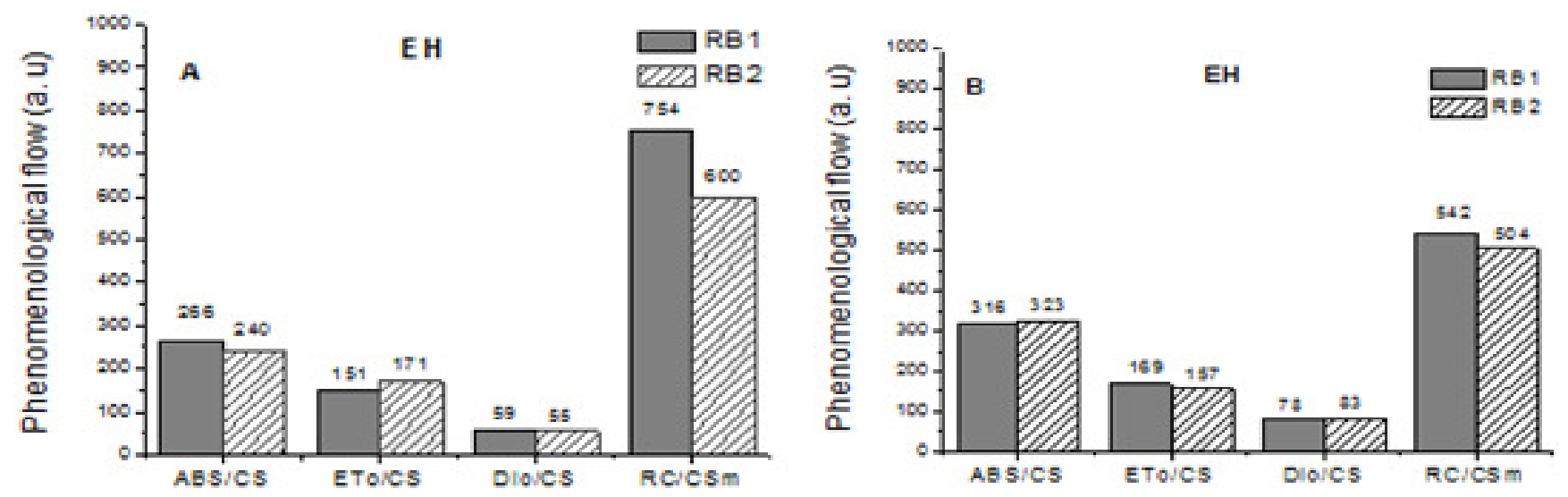

Figure 1. Comparison of the excitation cross section (CS) averages at the beginning of the experiment (A) and after 90 days (B) in seedlings of two varieties of Saccharum spp.: RB855536 (RB1) and RB 867515 (RB2) subjected to water stress.
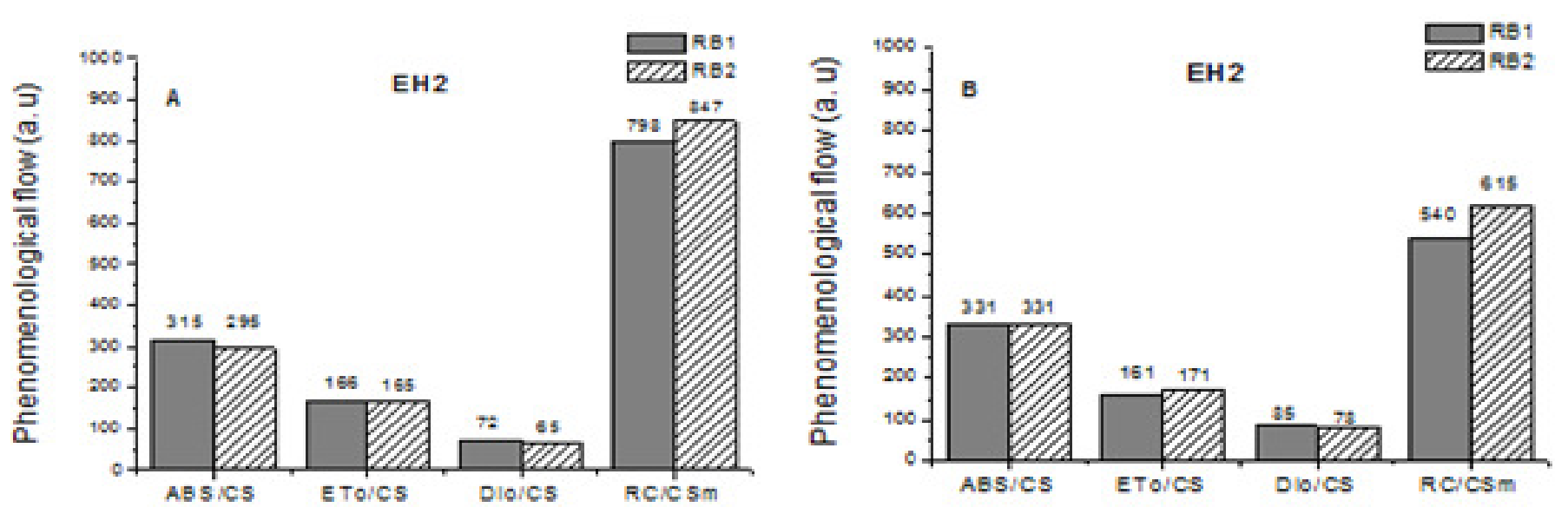

Figure 2. Comparison of the excitation cross section (CS) averages at the beginning of the experiment (A) and after 90 days (B) in seedlings of two varieties of Saccharum spp. RB855536 (RB1) and RB 867515 (RB2), subjected to water stress and 0.4 mmol/L aluminum sulfate $(\mathrm{EH} 2)$.

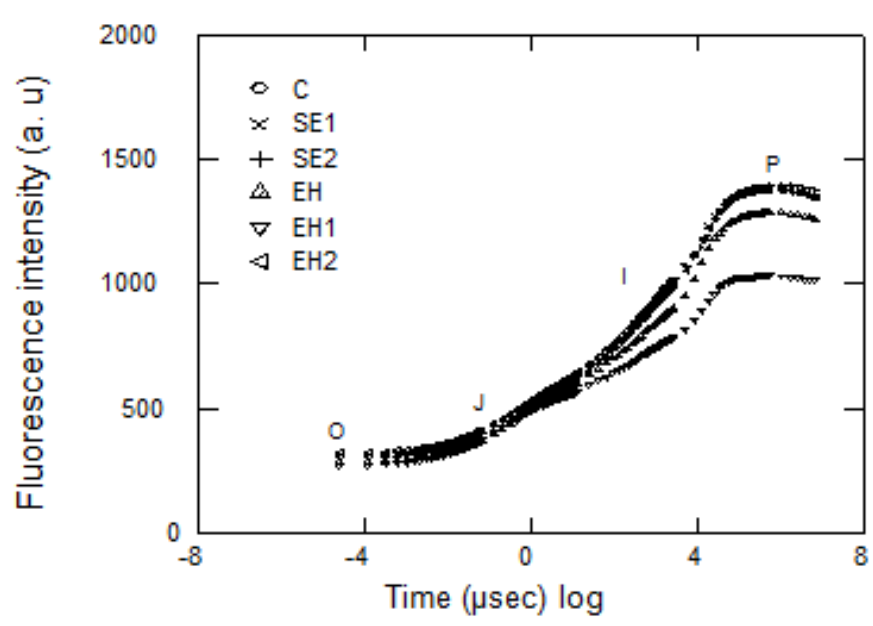

Figure 3. Comparison between the means of chlorophyll fluorescence transients in Saccharum spp. seedlings (RB855536 variety).

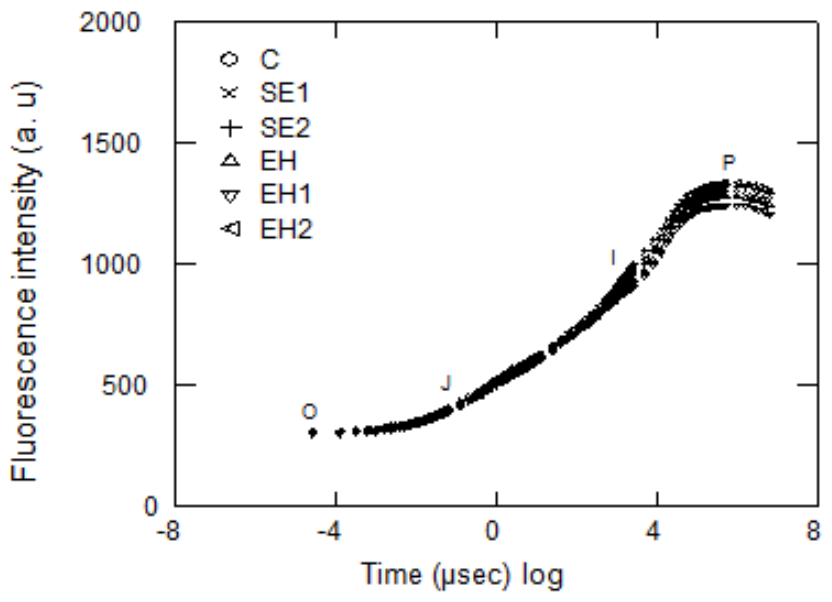

Figure 4. Comparison between the means of chlorophyll fluorescence transients in Saccharum spp. seedlings (RB867515 variety). 
photosynthetic complex, the test is highly accepted, for it reflects the accumulation of reduced electron carriers, pheophytin $(\mathrm{Ph})$ and quinones $(\mathrm{Qa})$ and $(\mathrm{Qb})$ in PSII (Strasser et al., 2004).

Abbaspoor and Streibig (2005), when testing clodinafop, a foliar selective post-emergent herbicide in oat and barley described changes in the Kautsky curve in relation to stage $\mathrm{J}$ of the OJIP test for both species. These changes were more accentuated for the oat in higher dosages of herbicide. Percival and Fraser (2001), in a study about stress by salinity and freezing over the foliar tissue of six Crataegus genotypes observed a decrease of sigmoidicity in the curves by means of the OJIP test. Sigmoidicity loss was also observed in an experiment with three varieties of rice, which were tolerant to submersion, conducted by Sarkar et al. (2004).

Gonçalves et al. (2010), when observing the OJIP transients of young andiroba (Carapa guianensis Aubl) and tonka bean (Dipteryx odorata (Aublet) Willd) plants exposed to the sun ( 45 days of experiment), verified a reduction in the curve elevation for both species, when compared to the initial OJIP transient in consequence of the reduction of Fm values. Normally, when plants are under stressing environments, the type of stress is not clearly identified by chlorophyll a fluorescence transient when data are presented in a linear way, however, when OJIP transient values are presented in the relative variable form, one can easily verify the type of stress (Lichtenthaler et al., 1998).

\section{Conclusions}

The results obtained by means of the OJIP test were the most efficient for the distinction of varieties, by sigmoicity loss in the curves from step $\mathrm{J}$ on, in plants kept under water stress. Variety RB1 (RB 8555536 ) has proved to be more responsive to treatments. For this variety, only the averages of initial fluorescence and quantum efficiency of PSIl did not vary at the end of the experiment, while variety RB2 (RB 867515) has proved to be more tolerant to treatments. The elevation of $\mathrm{Al}$ dosage suggests the interference of this element in the relations of energy absorption and electron transfer in PSII. The excitation variables of chlorophyll a per cross-section in variety RB2 suggested a better adjust of this variety to different experimental conditions.

Abbreviations: Chl-a, chlorophyll a; PAR, photosynthetically-active radiation; Fm, maximal fluorescence of dark-adapted state; Fo, minimal fluorescence of dark-adapted state; Fv, variable fluorescence; Fv/Fm, maximal quantum yield of PSII photochemistry; OJIP, fluorescence transient steps; PI, Performance or development index; PSII, photosystem II; Qa, plastoquinones of PSII; $\mathbf{Q b}$, secondary quinone acceptor of PSII; RB1, RB 8555536 sugar cane vaiety; RB2, RB867515 sugar cane variety; RCS, PSII reaction centers.

\section{REFERENCES}

Abbaspoor M, Streibig JC (2005). Clodinafop changes the chlorophyll fluorescence Induction curve. Weed Sci. 53:1-9.

Astolfi S, Zuchi S, Hubberten HM, Roberto Pinton R, Hoefgen R (2010). Supply of sulphur to S-deficient young barley seedlings restores their capability to cope with iron shortage. Oxford J. Exp. Bot. 61(3):799806.

Baker NR, Rosenqvist E (2004). Application of chlorophyll fluorescence can improve crop production strategies: an examination of future possibilities. J. Exp. Bot. 55:1607-1621.

Barazzouk S, Kamat PV, Hotchandani S (2005). Photoinduced Electron Transfer between Chlorophyll a and Gold Nanoparticles. J. Phys. Chem. B. 109(2):716-723.

Bolhàr-Nordenkampf HR, Long SP, Baker NR, Öquist G, Schreider U, Lechner EG (1989). Chlorophyll fluorescence as probe of the photosynthetic competence of leaves in the field: A review of current instrument. Functional Ecol. 3:497- 514

Caires ARL, Scherer MD, Santos TSB, Pontim BCA, Gavassoni WL, Oliveira SL (2010). Water stress response of conventional and transgenic soybean plants monitored by chlorophyll fluorescence. J. Fluorescence 20(3):645-649.

Carlin SD, Rhein AF de L, Santos DMM dos (2012). Efeito simultâneo da deficiência hídrica e do alumínio tóxico no solo na cultivar IAC915155 de cana-de-açúcar. Londrina Semina 33(2):553-564.

Chen LS, Qi YP, Smith BR, Liu XH (2005). Aluminum-induced decrease in $\mathrm{CO}_{2}$ assimilation in citrus seedlings is unaccompanied by decreased activities of key enzymes involved in $\mathrm{CO}_{2}$ assimilation. Victoria, Canadá. Tree Physiol. 25:317-324.

Ghannoum O, Conroy JP, DriscolL SP, Paul MJ, Foyer CH, Lawlor DW (2003). Nonstomatal limitations are responsible for drought-induced photosynthetic inhibition in four $\mathrm{C} 4$ grasses. New Phytologist 159:599-608

Gonçalves JFC, Santos Júnior (2005). U.M. Utilization of the chlorophyll a fluorescence technique as a tool for selecting tolerant species to environments of high irradiance. Brazilian J. Plant Physiol. 17:307313.

Goncalves JFC, Silva CE, Guimarães DG, Bernardes RS (2010). Transient Analysis of chlorophyll fluorescence of seedlings of Carapa guianensis Dipteryx odorata and subjected to two light environments. Amazonica Acta 40(1):89-98.

Godde D, Dannehl H (1994). Stress-induced chlorosis and increase in D1-protein turnover precede photoinhibition in spinach suffering under magnesium/sulphur deficiency. USA, Planta 195:291-300.

Gonçalves JF de C, Melo EG de F, Silva CEM da, Ferreira MJ, Justino GC (2012). Estratégias no uso da energia luminosa por plantas jovens de Genipa spruceana Steyerm submetidas ao alagamento. Acta Botanica Brasilica 26(2):391-398.

Jiang HX, Chen LS, Zheng JG, Han S, Tang N, Smith BR (2008). Aluminum-induced effects on Photosystem II photochemistry in Citrus leaves assessed by the chlorophyll a fluorescence transient. Victoria, Canadá. Tree Physiol. 28:1863-1871.

Li Q, Chen LS, Jiang HX, Tang N, Yang LT, Lin ZH, Li Y, Yang GH (2010). Effects of manganese-excess on $\mathrm{CO}_{2}$ assimilation, ribulose1,5-bisphosphate carboxylase/oxygenase, carbohydrates and photosynthetic electron transport of leaves, and antioxidant systems of leaves and roots in Citrus grandis seedlings. London, BMC Plant Biol. 10(42):1-16.

Lichtenthaler HK, Wenzel O, Buschmann C, Gitelson A (1998). Plant stress detection by reflectance and fluorescence, pp. 271-285. In: Annals New York Academy of Science.

Konrad MLF, Bezerra da Silva JA, Furlani PR, Machado EC (2005). Gas exchange and chlorophyll fluorescence in six coffee cultivars under aluminum stress. Bragantia, Campinas 64(3):339-347.

Molinari HBC, Marur CJ, Daros E, Campos MK, Carvalho JFRP, Filho JCB, Pereira LFP, Vieira LGE (2007). Evaluation of the stressinducible production of proline in transgenic sugarcane (Saccharum spp.): osmotic adjustment, chlorophyll fluorescence and oxidative 
stress Physiol. Plant. 130:218-229.

Moustaka M, Ouzounidou G, Lannoyer R (1995). Aluminum effects on photosynthesis and elemental uptake in an aluminum-tolerant and non-tolerant wheat cultivar. J. Plant Nutr. New York. 18:669-683.

National Supply Company (2011). Monitoring of the Brazilian crop: Cane Sugar, Harvest 2011/2012 First Survey - Maio/2011- National Supply Company. - Brasília: Conab, P. 20.

Oukarroum A, El Madidi S, Schansker G, Strasser RJ (2007). Probing the responses of barley cultivars (Hordeum vulgare L.) by chlorophyll a fluorescence OLKJIP under drought stress and re-watering. Environ. Exp. Bot. 60:438-446.

Pakrashi S, Dalai S, Prathna TC, Trivedi S, Myneni R, Raichur AM, Chandrasekaran N, Mukherjee A (2013). Cytotoxicity of aluminium oxide nanoparticles towards fresh water algal isolate at low exposure concentrations. Philadelphia. Aquatic Toxicol. 132-133:34-45.

Percival GC, Fraser GA (2001). Measurement of the salinity and Freezing tolerance of crataegus Genotypes using chlorophyll Fluorescence. J. Arboric. 27(5):233-245.

Ralph PJ, Burchett MD (1998). Photosynthetic response of Halophila ovalis to heavy metal stress. Philadelphia. Environ. Pollut. 103:91101.

Raij LC, Husaini Y, Mallick N (1998). pH-altered interaction of aluminum and fluoride on nutrient uptake, photosynthesis and other variables of Chlorella vulgaris. Aquatic Toxicol. Miami. 42:67-84.

Sadiq MI, Pakrashi S, Chandrasekaran N, Mukherjee A (2011). Studies on toxicity of aluminum oxide $\left(\mathrm{Al}_{2} \mathrm{O}_{3}\right)$ nanoparticles to microalgae species: Scenedesmus sp. and Chlorella sp. USA. J. Nanoparticle. Res. 13:3287-3299.
Sarkar RK, Panda D, Rao DN, Sharma SG (2004). Chlorophill fluorescence parameters as indicators of submergence tolerance in rice. Crop Manag. Physiol. Orissa - India, pp. 66-71.

Silva M de A, Jifon JL, Silva JAG da, Sharma V (2007). Use of physiological parameters as fast tools to screen for drought tolerance in sugarcane. Brazilian J. Plant Physiol. 19(3):193-201.

Steudle E (2000). Water uptake by roots: effects of water déficit. J. Exp. Bot. Oxford. 51(350):1531-1542.

Strasser A, Tsimilli-Michael M, Srivastava A (2004). Analysis of the fluorescence transient, in: Papageorgiou, G. C.; Govindjee (eds.), Chlorophyll fluorescence: A signature of photosynthesis. Advances in Photosynthesis and Respiration Series. Springer, Dordrecht, pp. 32362.

Tang C, Zengel Z; Diatloff E, Gazey C (2003). Responses of wheat end barley to liming on a sandy soil with subsoil acidity. Field Crops Res. 80:235-244.

Tester M, Bacic A (2005). Abiotic stress tolerance in grasses. From model plants to crop plants. Plant Physiol. 137:791-793.

Thach LB, Shapcott A, Schmidt S, Critchley C (2007). The OJIP fast fluorescence rise characterizes Graptophyllum species and their stress responses. Photosynthesis Res. 94:423-436.

Thavasi V, Renugopalakrishnan V, Jose R, Ramakrishna S (2009). Controlled electron injection and transport at materials interfaces in dye sensitized solar cells. Mater. Sci. Eng. R, Boston 63:81-99. 